\title{
A Case Report of an Intestinal Helminth Infection of Human Hymenolepiasis in Rural Gambia

\author{
Usman N Ikumapayi ${ }^{1}$, Chilel Sanyang ${ }^{1}$ and Dora IA Pereira ${ }^{1,2^{*}}$
}

${ }^{1}$ Medical Research Council Unit the Gambia, London School of Hygiene \& Tropical Medicine, Banjul, The Gambia

${ }^{2}$ Department of Pathology, University of Cambridge, UK

*Corresponding author: Dr. D Pereira, Department of Pathology, University of Cambridge, Tennis Court Road, Cambridge CB2 1QP, UK, Tel: +44-1223-764864

\begin{abstract}
Background: Hymenolepis nana, also called dwarf tapeworm infection, is an intestinal helminth not previously reported in The Gambia and only very rarely reported in West Africa.

Case presentation: We report a case of $H$. nana infection in a 29-month-old child living in a rural community of the north bank of the Upper River Region (URR) in The Gambia. The child presented with mild iron deficiency anaemia and granulocytosis but was otherwise mostly asymptomatic despite the moderate-intensity of infection.

Conclusions: We support treatment of $H$. nana infection even in largely asymptomatic children to prevent autoinfection and spread of this intestinal helminth in The Gambia and in other West African countries.

Keywords

Tapeworm, Hymenolepiasis, Hymenolepis nana, The Gambia, Children

Abbreviations

GCP: Good Clinical Practice; HAZ: Height-for-age z-score; IHAT-GUT: Acronym for the Iron Hydroxide Adipate Tartrate Supplementation Study; ICH: International Conference on Harmonisation; SD: Standard Deviation; URR: Upper River Region; WAZ: Weight-for-age z-score; WHO: World Health Organization; WHZ: Weight-for-height Z-score
\end{abstract}

\section{Background}

Hymenolepiasis is a neglected tropical disease and a type of helminthiasis infection which in humans is most commonly caused by Hymenolepis nana, often referred to as dwarf tapeworm. Hymenolepiasis frequently occurs in arid, warm and resource-poor regions [13], with the highest prevalence observed in children under 15-years-old, and an estimated 50 - 75 million carriers worldwide [4-7]. Very few reports of $H$. nana infection exist in the literature. There is a report of $H$. nana present in $28.6 \%$ of children living in the rural village of Touguri in Burkina Faso in 2011 [8]. Another report, in Ethiopia, showed that $H$. nana infection was present in $7.4 \%$ of children and that children infected with intestinal helminths had low haematocrit [9]. However, human infection with $H$. nana or $H$. diminuta have not been reported before in The Gambia or indeed in most West African countries and appears much more common in South East Asia [10].

$H$. nana belongs to the family Hymenolepididae and differs from all other human tapeworms because it does not require an intermediate host since the parasite is able to complete its entire cycle in a single host [11]. Due to this trait, the majority of infections occur as auto-infections, particularly in immunecompromised hosts, as a result of ingesting water or food contaminated by human faeces containing eggs [12]. Eggs passed in stool are immediately infective and this human-to-human transmission of eggs by the faecal-oral route is the most common route of infection, particularly in environments with poor hygiene and inappropriate sanitation. The ingested eggs hatch in the small intestine releasing a motile embryo, the oncosphere, which invades a villus and develops into the larval cysticercoid in about 4 weeks. The cysticercoid then ruptures the villus and attaches to

Citation: Ikumapayi UN, Sanyang C, Pereira DIA (2019) A Case Report of an Intestinal Helminth Infection of Human Hymenolepiasis in Rural Gambia. Clin Med Rev Case Rep 5:251. doi.org/10.23937/23783656/1410251

Accepted: January 02, 2019: Published: January 04, 2019

Copyright: () 2019 Ikumapayi UN, et al. This is an open-access article distributed under the terms of the Creative Commons Attribution License, which permits unrestricted use, distribution, and reproduction in any medium, provided the original author and source are credited. 


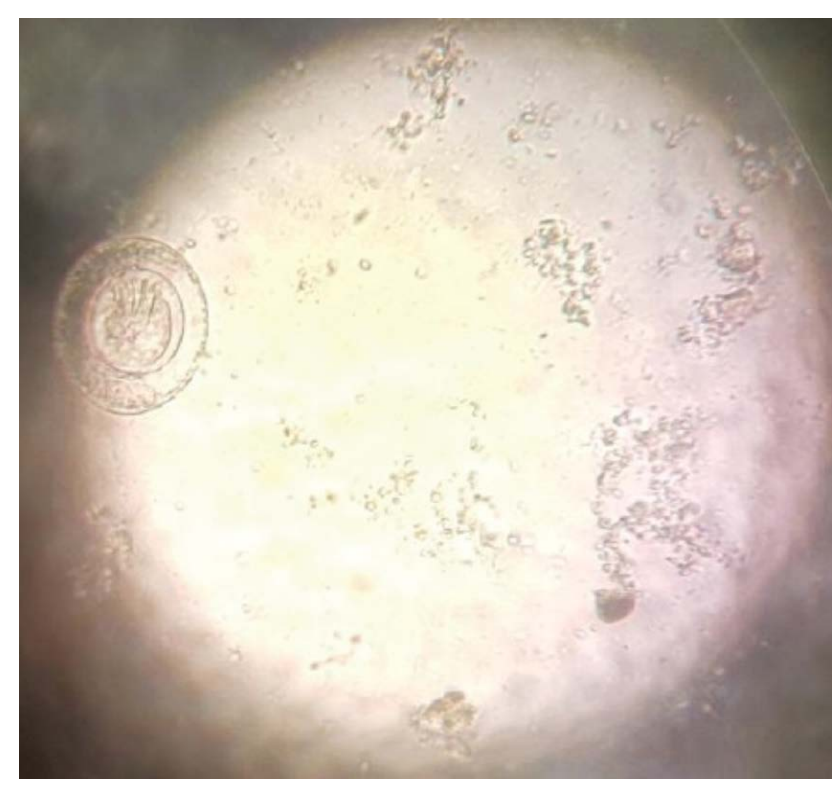

Figure 1: Image of the parasite identified as Hymenolepis nana. This picture was taken using a mobile phone facing the eyepiece whilst the object remains focused on the microscope stage with $\times 40$ objective. Eggs were 30-50 $\mu \mathrm{m}$ and egg morphology was confirmed as representative of $H$. nana eggs based on CDC guidelines (https://www.cdc.gov/ $\mathrm{dpdx}$ /hymenolepiasis/index.html).

the mucosal surface to mature into the adult tapeworm, the whole process takes approximately four weeks [11]. This parasite also has an indirect life cycle with humans and rodents as definitive hosts and arthropods, such as beetles and fleas, serving as intermediate hosts or vectors [10]. Accidental ingestion of contaminated food with infected arthropods is another possible route of infection. However, data on cases of hymenolepiasis attributed to food-borne infection are limited.

Mild infection with Hymenolepis nana is usually asymptomatic whilst heavy infection (> $500 \mathrm{eggs} / \mathrm{g}$ of stool), can cause severe morbidity in children, including anaemia, abdominal pain, diarrhoea, nausea, vomiting, headache, chronic urticaria, skin eruption, flatulence, weight loss, irritable behaviour and reduced growth [13-16]. The diagnosis of $H$. nana is usually made via microscopic identification of eggs in stool specimens [16].

Here we describe the first report in the literature of $H$. nana infection in a young Gambian child. To our knowledge, there are no other reports of hymenolepiasis in The Gambia.

\section{Case Presentation}

In our routine screening of 340 children, aged 6-35 months old and enrolled in an iron supplementation trial (namely IHAT-GUT, ClinicalTrials.gov identifier: NCT02941081), we found the case of a 29-month-old child with moderate infection of Hymenolepis nana. As part of the trial protocol, we examined 521 stool samples from study participants for intestinal parasites, using the Kato-Katz method based on duplicate slides
Table 1: Demographic characteristics of the child infected with Hymenolepis nana.

\begin{tabular}{|l|l|l|}
\hline Characteristic & Result $^{*}$ & Normal range \\
\hline Age (months) & 29 & \\
\hline WAZ (weight-for-age) & $-1 \mathrm{SD}$ & $-2 \mathrm{SD}-+$ 2SD \\
\hline HAZ (height-for-age) & $0 \mathrm{SD}$ & $-2 \mathrm{SD}-+$ 2SD \\
\hline WHZ (weight-for-height) & $-1 \mathrm{SD}$ & $-2 \mathrm{SD}-+$ 2SD \\
\hline Haemoglobin (g/dl) & $\mathbf{1 0 . 8}$ & $11.5-16.5$ \\
\hline Mean Cell Volume (fl) & $\mathbf{7 2 . 7}$ & $75.0-100.0$ \\
\hline Haematocrit $(\%)$ & $\mathbf{3 2 . 2}$ & $35.0-55.0$ \\
\hline Red Blood Cells $\left(\times 10^{-12} / \mathrm{L}\right)$ & 4.42 & $3.50-5.50$ \\
\hline White Blood Cells $\left(\times 10^{-9} / \mathrm{L}\right)$ & $\mathbf{1 7 . 8}$ & $3.5-10.0$ \\
\hline Granulocytes $\left(\times 10^{-9} / \mathrm{L}\right)$ & $\mathbf{1 2 . 5}$ & $1.2-8.0$ \\
\hline Ferritin $(\mu \mathrm{g} / \mathrm{l})$ & $\mathbf{1 2 . 9}$ & $>30$ \\
\hline
\end{tabular}

"Result: Outside the normal range for children $<5$ years in The Gambia are in bold.

as per current WHO recommendation [17]. The child with the stool sample harbouring $H$. nana eggs (Figure 1) was unique amongst the 72 children out of 340 (21\%) in whom intestinal parasites were present. The child presented with an infection intensity of 144 eggs/gram of stool and was mildly anaemic, with an $\mathrm{Hb}$ value of $10.8 \mathrm{~g} / \mathrm{dl}$, and iron deficient, with ferritin of $12.9 \mu \mathrm{g} / \mathrm{l}$. The child also had a high white blood cell count and high granulocyte count, indicative of infection (Table 1). Otherwise, the child was growing normally (Table 1 ) and, upon examination by the study nurses, was considered as an asymptomatic carrier of hymenolepiasis.

To prevent the spread of the infection, and irrespective of the asymptomatic status, the infected child was treated with praziquantel $20 \mathrm{mg} / \mathrm{kg}$ in a single oral dose following WHO guidelines, and was re-assessed 2 weeks later and considered free of the cestode.

\section{Discussion and Conclusions}

Hymenolepis nana is a rare intestinal cestode in The Gambia despite being one of the most common intestinal helminths worldwide, particularly in poor communities in warm and arid countries $[11,18]$. The dwarf tapeworm is among the few intestinal worms that can have a reproductive life cycle without requiring an intermediate host [19]. This ontogenetic aspect of the worm can lead to hyper-infection, with autoinfection persisting for many years if left untreated $[14,20]$.

Human $H$. nana infection is presumed to be mostly asymptomatic for intensities of up to 500 eggs/g of stool $[13,14]$. Indeed, in our investigation of this case, we confirmed that the child was largely asymptomatic, despite the moderate worm burden, and did not present with diarrhoea or abdominal pain or any other gastrointestinal symptom that has been associated with $H$. nana infection in children $[16,18,21]$. However, the child presented with anaemia and high white blood cell count due to high numbers of granulocytes, possibly eosinophilia, both conditions previously reported in indigenous Australian indigenous young children as as- 
sociated with $H$. nana infection [16]. Furthermore, it is possible that even this moderate-intensity of $H$. nana infection has contributed to the iron deficiency anaemia diagnosis in this child, possibly due to impaired iron absorption secondary to the inflammation caused by the parasitic infection. Additionally, during the follow-up visit to provide the child with praziquantel treatment, the nurses conducted a thorough interview with the mother and found that the child usually showed irritable behaviour and difficulty in settling down, as well as occasional diarrhoea, all symptoms previously associated with high-intensity of $H$. nana infection [13].

Rural Gambia is not known to be an endemic nor a pandemic region for hymenolepiasis. Some studies have associated environmental conditions with the spread of $H$. nana, particularly warm climate and temperate zones and remoteness $[2,3,22]$. The north bank of the URR in The Gambia is a rural and remote region reaching extreme high temperatures $\left(36^{\circ} \mathrm{C}-44^{\circ} \mathrm{C}\right)$ from February to June each year, and it is possible that these factors may have favoured the transmission and persistence of the parasite in the community. We speculate that this child was infected initially via contact with contaminated food or faeces, maybe from a foreigner travelling in the area, and that due to autoinfection, the infection intensity increased over time. Praziquantel, the recommended treatment for hymenolepiasis, is not routinely administered in The Gambia as part of the national deworming programme with mebendazole, which is largely ineffective against tapeworms [23]. This probably explains why the autoinfection was allowed to continue even when pre-school age children receive deworming tablets every 6 months.

Since the national deworming programmes do not target $H$. nana, we decided to treat all members of the household with praziquantel, following WHO treatment guidelines, as a measure to control the spread of this rare infection in that community.

We report the first case of $H$. nana infection in The Gambia where this worm is thought to be very rare. Due to the likelihood of autoinfection this tapeworm can reach very high infection intensity over time if left undiagnosed and untreated. Our investigation has shown possible spread of $H$. nana infection within remote rural communities in the absence of treatment. Hence, it is important to screen $\mathrm{H}$. nana alongside other intestinal parasites and to treat even if infection is thought to be asymptomatic.

\section{Acknowledgements}

We thank all the study participants from the IHATGUT study and other community members in the Wuli and Sandu districts of the URR, The Gambia. We thank the clinical, laboratory and support staff of the MRC Unit The Gambia at LSHTM.

\section{Funding}

The IHAT-GUT trial is supported by a Bill and Melinda Gates Foundation Grand Challenges New Interventions for Global Health award (OPP1140952). The Nutrition Group of the MRC Unit The Gambia at LSHTM are supported by core funding MC-A760-5QX00 to the MRC Unit The Gambia/MRC International Nutrition Group by the UK MRC and the UK Department for the International Development (DFID) under the MRC/DFID Concordat agreement. The funders had no role in study design, data collection and analysis, decision to publish, or preparation of this case report.

\section{Competing Interests}

The author(s) declared no potential conflicts of interest with respect to the research, authorship, and/ or publication of this article.

\section{Consent for Publication}

Written informed consent is obtained from all participants in the IHAT-GUT study and this covers publication of data in an anonymised form. This case report does not contain any identifiable information for the child in question and, as such, it maintains participant confidentiality.

\section{Availability of Data and Materials}

All data generated or analysed during this study are included in this published article.

\section{Authors' Contributions}

DIAP designed and coordinated the study, analysed data and contributed to the draft and reviewing of the manuscript. UNI wrote the first draft of the manuscript and conducted stool sample analysis. CS conducted blood sample analysis, helped with the stool sample analysis and contributed to the draft of the manuscript. All the authors read and approved the final version of the manuscript.

\section{References}

1. Diaz E, Mondragon J, Ramirez E, Bernal R (2003) Epidemiology and control of intestinal parasites with nitazoxanide in children in Mexico. Am J Trop Med Hyg 68: 384-385.

2. Jacobsen KH, Ribeiro PS, Quist BK, Rydbeck BV (2007) Prevalence of intestinal parasites in young Quichua children in the highlands of rural Ecuador. J Health Popul Nutr 25: 399-405.

3. Mirdha BR, Samantray JC (2002) Hymenolepis nana: A common cause of paediatric diarrhoea in urban slum dwellers in India. J Trop Pediatr 48: 331-334.

4. Anorital (2014) Kajian Penyakit Kecacingan Hymenolepis Nana. Jurnal Biotek Medisiana Indonesia 3: 37-47.

5. Craig $P$, Ito A (2007) Intestinal cestodes. Curr Opin Infect Dis 20: $524-532$.

6. Garcia LS (2001) Diagnostic medical parasitology. (4 ${ }^{\text {th }}$ edn), ASM Press, Washington, DC. 
7. Hench J, Cathomas G, Dettmer MS (2017) Hymenolepis nana: A case report of a perfect IBD camouflage warrior. Medicine (Baltimore) 96: e9146.

8. Fortunato S, Castagna B, Monteleone MR, Pierro R, Cringoli G, et al. (2014) Parasite prevalence in a village in Burkina Faso: The contribution of new techniques. J Infect Dev Ctries 8: 670-675.

9. Abera B, Alem G, Yimer M, Herrador Z (2013) Epidemiology of soil-transmitted helminths, Schistosoma mansoni, and haematocrit values among schoolchildren in Ethiopia. J Infect Dev Ctries 7: 253-260.

10. Thompson RC (2015) Neglected zoonotic helminths: Hymenolepis nana, Echinococcus canadensis and Ancylostoma ceylanicum. Clin Microbiol Infect 21: 426-432.

11. Schantz PM (1996) Tapeworms (cestodiasis). Gastroenterol Clin North Am 25: 637-653.

12. Acha PN, Szyfres B (2003) Zoonoses and communicable diseases common to man and animals. ( $3^{\text {rd }}$ edn), Volume III, Pan American Health Organization, Washington, DC.

13. Cabada MM, Morales ML, Lopez M, Reynolds ST, Vilchez EC, et al. (2016) Hymenolepis nana Impact Among Children in the Highlands of Cusco, Peru: An Emerging Neglected Parasite Infection. Am J Trop Med Hyg 95: 1031-1036.

14. Kim BJ, Song KS, Kong HH, Cha HJ, Ock M (2014) Heavy Hymenolepis nana Infection Possibly Through Organic Foods: Report of a Case. Korean J Parasitol 52: 85-87.

15. Sungkar S, Sianturi I, Kusumowidagdo G (2017) Human Infection with Hymenolepis Spp.: Case Reports from East Indonesia. Arch Parasitol 1: 104.
16. Willcocks B, McAuliffe GN, Baird RW (2015) Dwarf tapeworm (Hymenolepis nana): Characteristics in the Northern Territory 2002-2013. J Paediatr Child Health 51: 982-987.

17. Committee WHOE (2002) Prevention and control of schistosomiasis and soil-transmitted helminthiasis. World Health Organ Tech Rep Ser 912: 1-57.

18. Hamid MMA, Eljack IA, Osman MKM, Elaagip AH, Muneer MS (2015) The prevalence of Hymenolepis nana among preschool children of displacement communities in Khartoum state, Sudan: A cross-sectional study. Travel Med Infect Di 13: 172-177.

19. Olson PD, Yoder K, Fajardo LGL, Marty AM, van de Pas S, et al. (2003) Lethal invasive cestodiasis in immunosuppressed patients. J Infect Dis 187: 1962-1966.

20. Cho SC, Lee HL, Lee OY, Yoon BC, Choi HS, et al. (2009) Hymenolepis nana infection of the colon in an adult male. Gastrointest Endosc 70: 784-785.

21. Romero-Cabello R, Godinez-Hana L, Gutierrez-Quiroz M (1991) Clinical aspects of hymenolepiasis in pediatrics. Bol Med Hosp Infant Mex 48: 101-105.

22. Speare R, Latasi FF, Nelesone T, Harmen S, Melrose W, et al. (2006) Prevalence of soil transmitted nematodes on Nukufetau, a remote Pacific island in Tuvalu. BMC Infect Dis 6: 110.

23. Soares Magalhaes RJ, Fancony C, Gamboa D, Langa AJ, Sousa-Figueiredo JC, et al. (2013) Extending helminth control beyond STH and schistosomiasis: the case of human hymenolepiasis. PLoS Negl Trop Dis 7: e2321. 